\title{
Inheritance and Molecular Characterization of a Novel Mutated AHAS Gene Responsible for the Resistance of AHAS-Inhibiting Herbicides in Rapeseed (Brassica napus L.)
}

\author{
Qianxin Huang ${ }^{1,2}$, Jinyang Lv ${ }^{1,3}$, Yanyan Sun ${ }^{1,2}$, Hongmei Wang ${ }^{1,2}$, Yuan Guo ${ }^{1,2}$, \\ Gaoping $\mathrm{Qu}{ }^{1,2}$ and Shengwu $\mathrm{Hu}{ }^{1,2, *(D)}$ \\ 1 State Key Laboratory of Crop Stress Biology in Arid Areas, Yangling 712100, China; \\ qianxinh@163.com (Q.H.); lvjy890727@163.com (J.L.); 15929800833@163.com (Y.S.); \\ 18729362103@163.com (H.W.); guoyuan2109@163.com (Y.G.); qugp68@163.com (G.Q.) \\ 2 College of Agronomy, Northwest A\&F University, Yangling 712100, China \\ 3 College of Life Sciences, Northwest A\&F University, Yangling 712100, China \\ * Correspondence: swhu83251@nwsuaf.edu.cn; Tel./Fx: +86-29-87082604
}

Received: 3 January 2020; Accepted: 14 February 2020; Published: 17 February 2020

\begin{abstract}
The use of herbicides is an effective and economic way to control weeds, but their availability for rapeseed is limited due to the shortage of herbicide-resistant cultivars in China. The single-point mutation in the acetohydroxyacid synthase (AHAS) gene can lead to AHAS-inhibiting herbicide resistance. In this study, the inheritance and molecular characterization of the tribenuron-methyl (TBM)-resistant rapeseed (Brassica napus L.) mutant, K5, are performed. Results indicated that TBM-resistance of K5 was controlled by one dominant allele at a single nuclear gene locus. The novel substitution of cytosine with thymine at position 544 in BnAHAS1 was identified in K5, leading to the alteration of proline with serine at position 182 in BnAHAS1. The TBM-resistance of $K 5$ was approximately 100 times that of its wild-type ZS9, and $K 5$ also showed cross-resistance to bensufuron-methyl and monosulfuron-ester sodium. The BnAHAS1 ${ }^{544 T}$ transgenic Arabidopsis exhibited higher TBM-resistance than that of its wild-type, which confirmed that BnAHAS1 ${ }^{544 T}$ was responsible for the herbicide resistance of K5. Simultaneously, an allele-specific marker was developed to quickly distinguish the heterozygous and homozygous mutated alleles BnAHAS1 ${ }^{544 T}$. In addition, a method for the fast screening of TBM-resistant plants at the cotyledon stage was developed. Our research identified and molecularly characterized one novel mutative AHAS allele in B. napus and laid a foundation for developing herbicide-resistant rapeseed cultivars.
\end{abstract}

Keywords: rapeseed (Brassica napus L.); acetohydroxyacid synthase; single-point mutation; herbicide resistance

\section{Introduction}

Rapeseed (Brassica napus L.), an important oilseed crop worldwide, is planted in approximately 75 million ha of land in China annually over the last decade [1] and supplies $60 \%$ of the vegetable oils in the Chinese market. In recent years, weed control is becoming a challenge in rapeseed fields due to the rapid extension of rapeseed mechanized production $[2,3]$. The use of herbicide-resistant varieties is an economical way to control weeds in modern agriculture [4]. However, the availability of selective herbicides for rapeseed is limited due to a shortage of herbicide-resistant cultivars in China $[5,6]$. To date, the primary measurement to control weeds in rapeseed fields in China is to apply acetochlor as a preemergence herbicide. In addition, two postemergence herbicides, chloropyridine acid and benazolin-ethyl, can be used for controlling broadleaf weeds in rapeseed fields [7]. 
More than one-sixth (54/302) of the globally registered herbicides are acetohydroxyacid synthase (AHAS, EC 2.2.1.6)-inhibiting herbicides [8]. These kinds of herbicides kill susceptible plants by suppressing the AHAS enzyme activity, also known as acetolactate synthase (ALS), which plays an important role in the biosynthetic pathway of branched-chain amino acids valine, leucine and isoleucine at the first step [9-11]. Since the first introduction of AHAS-inhibiting herbicides into the agronomic production in the 1980s, they have become a valuable tool in controlling weeds due to their low dosage, environmental friendliness, low mammalian toxicity, wide crop selectivity and high efficacy [8]. These kinds of herbicides can be classified into five groups, namely, sulfonylureas (SU), sulfonylamino-carbonyltriazolinones, imidazolinones (IMI), triazolopyrimidines and pyrimidinylthiobenzoates [12-15]. Tribenuron-methyl (TBM), an SU herbicide, was produced by the Dupont Company in the early 1980s and introduced to China in 1988 [16]. At present, TBM is used in broadleaf weed control across wheat fields in China and accounts for over half of the total herbicide usage due to its high efficacy at low dosage, low effect on nontarget organisms and high selectivity [17]. However, conventional rapeseed varieties are sensitive to TBM due to the lack of resistant genes. If the rapeseed variety with TBM-resistance can be developed, then the prescription of the combination of TBM with the existing monocotyledonous herbicides which are used in rapeseed fields can provide an alternative way to effectively control weeds in rapeseed fields.

$A H A S$ is particularly vulnerable to gene mutations and substitutions, which can convert $A H A S$ from the herbicide-sensitive form to the herbicide-resistant form [9]. To date, the point mutations of AHASs primarily occur in their conservative domains. These mutations occur in the eight mutation sites Ala122, Pro197, Ala205, Asp376, Arg377, Trp574, Ser653 and Gly654 in AHASs (in reference to Arabidopsis thaliana L.) $[18,19]$. Three functional genes BnAHAS1, BnAHAS2 and BnAHAS3 and two pseudogenes BnAHAS4 and BnAHAS5 have been identified in rapeseed (B. napus) [20]. In B. napus, several AHAS-inhibiting herbicide-resistant mutants have been obtained through spontaneous and chemical mutagenesis by using ethyl nitrosourea or ethyl methyl sulfonate (EMS). These mutants include PM1 and M9 that harbor Asp instead of Ser at position 653 of BnAHAS1 (S653A in BnAHAS1), PM2 and M342 that harbor T574L in BnAHAS3 and M45 that harbors P197S/L in BnAHAS3 [6,21-24] and have been reported to be resistant to one or more dissimilar AHAS-targeted herbicides. These AHAS mutants have been used to develop herbicide-resistant rapeseed varieties [25] and are recommended to be used as male parents in chemical-induced male sterility hybrid seed production [21,26].

Herbicide-resistant rapeseed was first registered and cultivated in the 1980s in Canada. At present, the herbicide-resistant rapeseed varieties are dominant in the seed market of Canada [27]. The primary types of herbicide-resistant rapeseed in Canada include the glufosinate-, glyphosate- and IMI-resistant varieties registered by the Bayer, Monsanto and BASF companies, respectively. These herbicide-resistant rapeseed varieties are subject to international intellectual property protection, in which expensive patent fees should be paid for their commercial cultivation. In addition, the glyphosate- and glufosinate-resistant rapeseed are transgenic varieties, which are not yet approved for commercial cultivation in China. At present, China lacks herbicide-resistant cultivars with independent intellectual property, which has become the bottleneck of the rapeseed industry. Therefore, the development of herbicide-resistant rapeseed varieties and their corresponding herbicide formulations are important for the development of the rapeseed industry.

Previously, our research group has identified three TBM-resistant rapeseed mutants derived from Zhongshuang No.9 (ZS9) via EMS mutagenesis and TBM foliar-spray screening [5,28]. In this study, one of the TBM-resistant rapeseed mutants (K5) was characterized. The objectives of the present investigation were to: (1) reveal the resistance or cross-resistance of $K 5$ to different herbicides, (2) determine the mode of inheritance and the molecular mechanisms of herbicide resistance and (3) develop a rapid method for screening herbicide-resistant materials. The obtained results will lay a foundation for developing herbicide-resistant varieties in rapeseed. 


\section{Results}

\subsection{Cross-Resistance of the Mutant Line K5 to Different Herbicides}

K5 and ZS9 were treated with 10 different herbicides at the 4-6 leaf stage to investigate the responses of the mutant line $K 5$ to different herbicides. The tested herbicides and the used rates are detailed in the Section 4.1. Results indicated that the line K5 exhibited resistance to three herbicides: TBM, bensufuron-methyl (BSM) and monosulfuron-ester sodium (MES) (Figure S1). However, it was susceptible to imidazole nicotinic, florasulam (FU), carfentrazone-ethyl (CFE), sulfometuron methyl ester (SME), nicosulfuron (NSF), glyphosate and glufosinate $\backslash$. The line ZS9 was almost susceptible to all the application rates of the tested herbicides. 21 DAT (days after treatment), the ZS9 individual plants showed a variety of symptoms, such as yellow, curly and withered leaves and purple veins, which were particularly evident in newly growing leaves (Figure S1).

Five traits, namely, phytotoxicity index, the leaf angle, leaf numbers, fresh weight and dry weight, were investigated after treating the lines ZS9 and K5 with three herbicides (TBM, BSM and MES) at different rates. The analysis of variance indicated that only BSM treatments have no effect on leaf angle, leaf numbers, fresh weight and dry weight of K5, except traits of lines ZS9 and K5 under other tested rates of herbicides were remarkably affected (Tables S1 and S2).

The phytotoxicity index and the inhibition rates of the leaf angle, leaf numbers and fresh and dry weights of K5 increased more slowly compared with those of ZS9 at increasing TBM rates (Table S2). ZS9 showed low-level resistance to TBM. Under the treatment of $0.06 \mathrm{~g}$ a.i. $\mathrm{ha}^{-1} \mathrm{TBM}$ in a volume of $300 \mathrm{~L} \mathrm{ha}^{-1}$, no apparent phytotoxicity was observed in ZS9 individuals 21 DAT (Figure S1). However, ZS9 showed a variety of phytotoxicity when treated with other rates of TBM $\geq 0.15 \mathrm{~g}$ a.i. ha ${ }^{-1}$, and all individual plants died under the treatment of $0.6 \mathrm{~g}$ a.i. ha ${ }^{-1} \mathrm{TBM}$ (Figure 1 and Table 1). The mutant line K5 showed high-level resistance to TBM. No apparent difference was observed between the TBM-free treatment and TBM treatments at rates up to $15 \mathrm{~g}$ a.i. ha ${ }^{-1}$ (Figure S1). When the TBM rate increased to $30 \mathrm{~g}$ a.i. $\mathrm{ha}^{-1}$, only young leaves were injured. When the TBM rate increased to $60 \mathrm{~g}$ a.i. $\mathrm{ha}^{-1}$, individual plants were injured (Figure S1); however, most of the plants can survive after winter. The fresh and dry weights $I_{50}$ of $K 5$ were approximately 70 and 97 times, respectively, that of ZS9 (Table 1). The lethal rate of TBM for K5 was at least 100 times that of ZS9 (Table 1). The safety rate of TBM for K5 was $15 \mathrm{~g}$ a.i. ha ${ }^{-1}$, which was approximately 250 times that of ZS9 (Table 1).

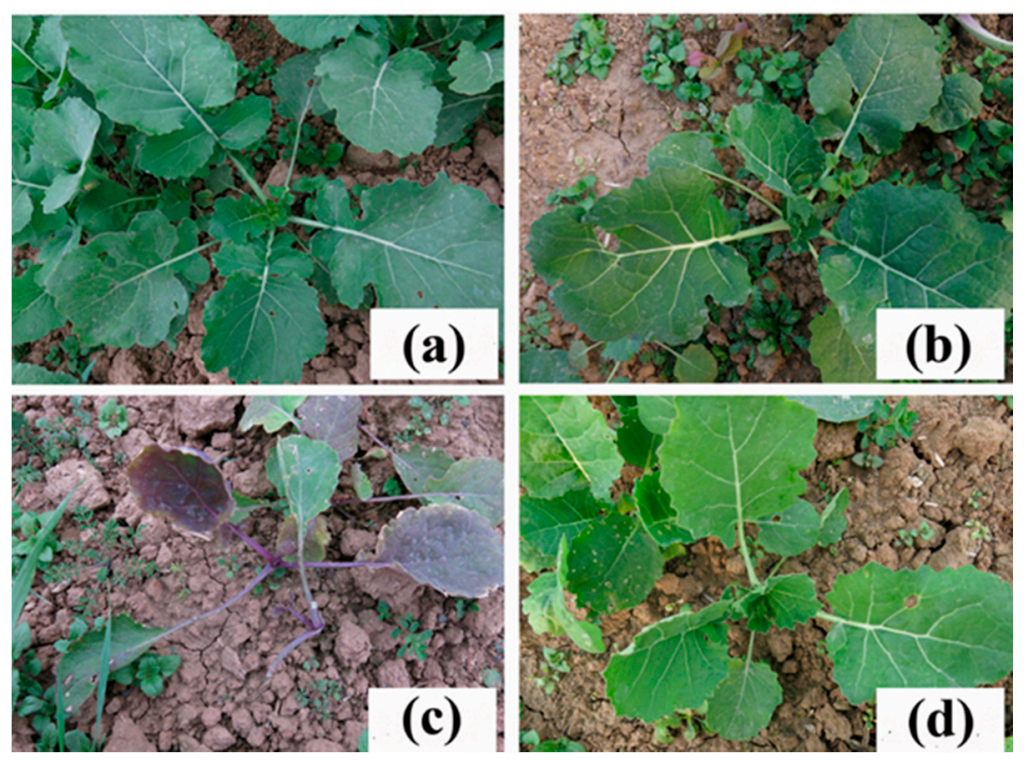

Figure 1. Resistance of the rapeseed mutant line $K 5$ to tribenuron-methyl (TBM). (a) Untreated wild-type ZS9 plants. (b) Untreated line K5 plants. (c) ZS9 plants treated with 0.6 g a.i. ha ${ }^{-1}$ TBM. (d) K5 plants treated with $0.6 \mathrm{~g}$ a.i. $\mathrm{ha}^{-1} \mathrm{TBM}$. 
Table 1. Cross-resistance of the mutant line $K 5$ to three different herbicides.

\begin{tabular}{|c|c|c|c|c|c|}
\hline \multirow{2}{*}{ Herbicide } & \multirow{2}{*}{ Lines } & \multicolumn{2}{|c|}{$I_{50}\left(g\right.$ a.i. ha $\left.a^{-1}\right)$} & \multirow{2}{*}{$\begin{array}{l}\text { Lethal Rate } \\
\left(\mathrm{g} \text { a.i. } \mathrm{ha}^{-1}\right)\end{array}$} & \multirow{2}{*}{$\begin{array}{l}\text { Safety Rate } \\
\left(\mathrm{g} \text { a.i. } \mathrm{ha}^{-1}\right)\end{array}$} \\
\hline & & Fresh Weight & Dry Weight & & \\
\hline \multirow{2}{*}{ TBM } & ZS9 & $0.36 \pm 0.06$ & $0.30 \pm 0.06$ & 0.60 & 0.06 \\
\hline & K5 & $25.38 \pm 11.67^{* *}$ & $28.98 \pm 12.99$ ** & $60.00-150.00$ & 15.00 \\
\hline \multirow{2}{*}{ BSM } & ZS9 & $0.27 \pm 0.12$ & $0.30 \pm 0.15$ & 1.50 & 0.15 \\
\hline & K5 & $14.91 \pm 0.00 * *$ & $8.79 \pm 3.12 * *$ & $>27.00$ & 18.00 \\
\hline \multirow{2}{*}{ MES } & ZS9 & $0.39 \pm 0.12$ & $0.36 \pm 0.12$ & 1.00 & 0.10 \\
\hline & K5 & $19.05 \pm 4.59 * *$ & $19.74 \pm 2.61^{* *}$ & $30.00-50.00$ & 10.00 \\
\hline
\end{tabular}

TBM, tribenuron-methyl; BSM, bensufuron-methyl; MES, monosulfuron-ester sodium; and ZS9, Zhongshuang No.9. $I_{50}$ is the herbicide rate required to reduce fresh/dry weight by $50 \%$. ${ }^{* *}$ indicated a significant difference between ZS9 and K5 in the tested traits at a 0.01 level.

The experimental results of BSM indicated that significant differences existed among the tested rates of BSM for the five traits of ZS9. However, except for the phytotoxicity index, the traits (leaf angle, leaf numbers, and fresh and dry weights) did not show significant differences for K5 (Table S1). ZS9 was almost normal after being treated with different rates of $\mathrm{BSM} \leq 0.15 \mathrm{~g}$ a.i. ha ${ }^{-1}$. ZS9 individuals were slightly injured after being treated with $0.3 \mathrm{~g}$ a.i. $\mathrm{ha}^{-1} \mathrm{BSM}$ (Figure S1). The highest rate of BSM used was not lethal for K5 (Figure S1 and Table S2). K5 appeared almost normal after being treated with different rates of BSM $\leq 18 \mathrm{~g}$ a.i. $\mathrm{ha}^{-1}$. Based on the fresh and dry weights $I_{50}, K 5$ showed approximately 55 and 30 times BSM resistance, respectively, that of ZS9 (Table 1). The lethal and safety rates of BSM for K5 were at least 18 and approximately 120 times, respectively, that of ZS9 (Table 1). Therefore, K5 conferred 30 times BSM-resistance than that of the ZS9.

The MES results indicated that significant differences existed among the tested rates of MES in the five traits of the ZS9 and K5 lines (Table S1). ZS9 was almost normal after being treated with different rates of MES $\leq 0.1 \mathrm{~g}$ a.i. $\mathrm{ha}^{-1}$. ZS9 individuals were slightly injured after being treated with $0.2 \mathrm{~g}$ a.i. ha ${ }^{-1}$ MES (Figure S1). K5 appeared almost normal after being treated with different rates of MES $\leq 10 \mathrm{~g}$ a.i. $\mathrm{ha}^{-1}$. Based on the fresh and dry weights $I_{50}, K 5$ showed approximately 49 and 55 times MES resistance, respectively, that of ZS9 (Table 1). The lethal and safety rates of MES for K5 was approximately 30 times and 100 times, respectively, that of ZS9 (Table 1). Therefore, K5 conferred 30 times MES resistance than that of ZS9.

In general, the mutant line $K 5$ conferred a high-level resistance to TBM and showed resistance to BSM and MES. The safety rate of TBM for K5 (15 g a.i. ha $\left.{ }^{-1}\right)$ approached the recommended dosage for weed control in wheat crops $\left(13.5-22 \mathrm{~g}\right.$ a.i. $\left.\mathrm{ha}^{-1}\right)$.

\subsection{AHAS Enzyme Activity Assay}

The enzyme activities of $K 5$ and ZS9 seedlings were tested after being treated with different rates of TBM, BSM and MES to determine whether the resistance to three herbicides (TBM, BSM and MES) in the mutant line $K 5$ is the result of the gain-of-function mutation of AHAS. The molecular weight of AHAS extracted from ZS9 and K5 seedlings free from any herbicide treatments was approximately $58-66 \mathrm{kDa}$ (Figure 2d). The AHAS-specific activities in ZS9 and K5 seedlings were $0.098 \pm 0.011$ and $0.075 \pm 0.013 \mathrm{U} / \mathrm{mg}$, respectively. Significant differences did not exist between the two lines $(\mathrm{t}=2.8$, $p=0.13)$, which indicated that the mutation in $K 5$ did not affect its AHAS activity. The AHAS relative enzyme activity of the ZS9 decreased suddenly with the increased TBM rate, particularly for the rates of TBM $\geq 0.6 \mathrm{~g}$ a.i. $\mathrm{ha}^{-1}$ (Figure 2a). By contrast, the AHAS relative enzyme activity of $K 5$ decreased gradually with the increased TBM rate, and TBM rates $<6 \mathrm{~g}$ a.i. $\mathrm{ha}^{-1}$ rarely affected the AHAS activity (Figure 2a). The AHAS activity of $K 5$ can be inhibited to $50 \%$ of its original level $\left(I_{50}\right)$ with $41.1 \mathrm{~g}$ a.i. ha ${ }^{-1}$ TBM treatment, which was approximately 250 times that of ZS9 $\left(I_{50}=0.17 \mathrm{~g}\right.$ a.i. $\left.\mathrm{ha}^{-1}\right)$. Under the treatment of BSM or MES, changes in the enzyme relative activity of K5 and ZS9 seedlings showed a similar trend to that of TBM treatments (Figure $2 b, c)$. The in vitro enzyme activity of AHAS treated with different rates of TBM was also detected, and results indicated that the AHAS activity of the 
ZS9 was suppressed by adding TBM solution and decreased by adding $1.0 \mathrm{mg} \mathrm{L}^{-1} \mathrm{TBM}$. However, the AHAS activity of $K 5$ was not inhibited significantly at the test rates of TBM (Figure S2). Simultaneously, the AHAS enzyme activity was tested from herbicide-sprayed materials or tested the in vitro way, but results revealed that the AHAS enzyme activity of K5 was less inhibited than that of ZS9 when treated with three different herbicides, which indicated that the resistance of $K 5$ was due to a gain-of-function mutation in the AHAS genes and not because of the overproduction of AHAS.

(a)

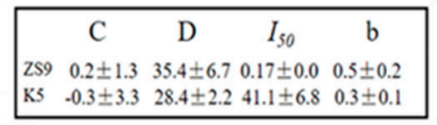

TBM concentration for $Z S 9$ (g a.i.ha')

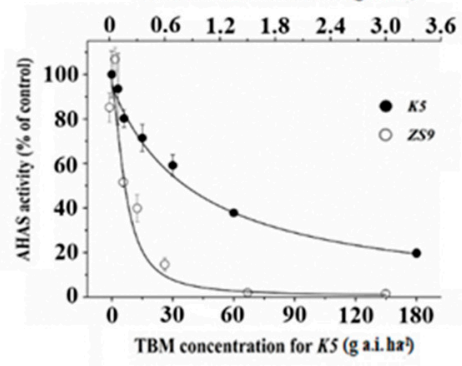

(c)

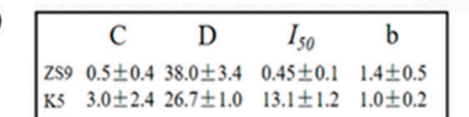

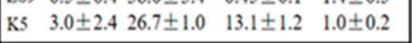

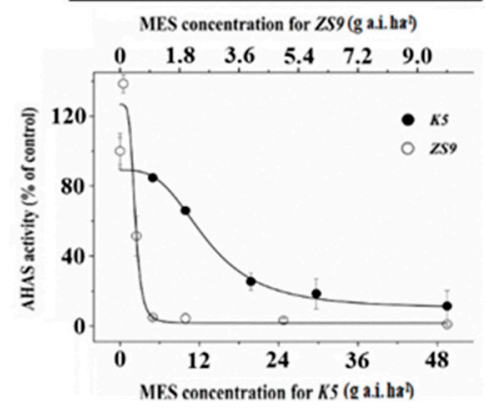

(b)
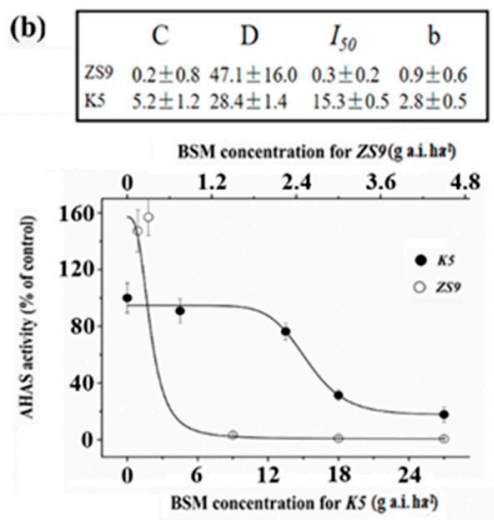

(d)

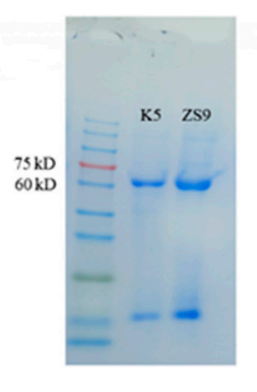

Figure 2. Activity assay of AHAS of ZS9 and K5 after spraying with three different herbicides. $(\mathbf{a}-\mathbf{c})$ Relative AHAS activity of rapeseed ZS9 and the mutant $K 5$ after spraying with tribenuron-methyl (TBM) (a), bensufuron-methyl (BSM) (b) and monosulfuron-ester sodium (MES) (c). (d) Sodium dodecyl sulfate-polyacrylamide gel electrophoresis (SDS-PAGE) of AHAS enzyme extracted from fresh leaves of herbicide-free K5 and ZS9. In the absence of herbicides, no significant difference was detected in the AHAS average specific activity $(\mathrm{U} / \mathrm{mg}$ protein/h) between $K 5(0.075 \pm 0.013, n=4)$ and ZS9 $(0.098 \pm 0.011, n=4)$.

\subsection{Genetic Investigation of TBM-Resistance of the Mutant Line K5}

The seedlings of $\mathrm{F}_{1}, \mathrm{BC}_{1}$ and $\mathrm{F}_{2}$ progenies derived from $\mathrm{K} 5$ and two susceptible parents, $S H 11$ and ZS9, were foliar sprayed with $4.5 \mathrm{~g}$ a.i. $\mathrm{ha}^{-1} \mathrm{TBM}$ at the $4-6$ leaf stage to determine the resistance inheritance of $K 5$. Results indicated that two $F_{1}$ populations from all reciprocal crosses were resistant to TBM (Table 2), and individual plants did not die in the whole growth period. The $\mathrm{F}_{2}$ population derived from the cross between K5 and ZS9 was segregated at a ratio of 1059 resistant plants:350 susceptible plants. The $\mathrm{BC}_{1}$ population was segregated at a ratio of 114 resistant plants:103 susceptible plants. The goodness-of-fit test indicated that the segregation of resistant and susceptible plants fits the expected Mendelian ratios of 3:1 and 1:1, respectively $\left(\chi^{2}{ }_{c}=0.02, p=0.89\right.$ and $\chi^{2}{ }_{c}=0.28, p=0.60$; Table 2). The $\mathrm{F}_{2}$ and $\mathrm{BC}_{1}$ populations derived from the cross between the $K 5$ and the $S H 11$ also obtained similar results $\left(\chi^{2}{ }_{c}=0.25, p=0.62\right.$ and $\chi^{2}{ }_{c}=0, p=1$; Table 2$)$. These results indicated that the TBM 
resistance of $K 5$ was controlled by one pair of nuclear genes, which had dominant resistance but no cytoplasmic effect.

Table 2. Inheritance of the tribenuron-methyl resistance in the mutant line K5.

\begin{tabular}{|c|c|c|c|c|c|c|}
\hline $\begin{array}{l}\text { Cross and } \\
\text { Population }\end{array}$ & $\begin{array}{c}\text { Resistant } \\
\text { Plants }\end{array}$ & $\begin{array}{c}\text { Sensitive } \\
\text { Plants }\end{array}$ & $\begin{array}{c}\text { Expected } \\
\text { Ratio }\end{array}$ & Ratio & $x^{2}{ }_{c}$ & $\mathbf{P}$ \\
\hline \multicolumn{7}{|c|}{$K 5 \times Z S 9$} \\
\hline $\mathrm{F}_{1}$ & 89 & 0 & - & - & - & - \\
\hline $\mathrm{RF}_{1}$ & 94 & 0 & - & - & - & - \\
\hline $\mathrm{BC}_{1}$ & 114 & 103 & $1: 1$ & $1.10: 1$ & 0.28 & 0.60 \\
\hline $\mathrm{F}_{2}$ & 1059 & 350 & $3: 1$ & $3.02: 1$ & 0.02 & 0.89 \\
\hline \multicolumn{7}{|c|}{$K 5 \times S H 11$} \\
\hline $\mathrm{F}_{1}$ & 172 & 0 & - & - & - & - \\
\hline $\mathrm{RF}_{1}$ & 164 & 0 & - & - & - & - \\
\hline $\mathrm{BC}_{1}$ & 177 & 172 & $1: 1$ & $1.03: 1$ & 0 & 1 \\
\hline $\mathrm{F}_{2}$ & 403 & 127 & $3: 1$ & $3.17: 1$ & 0.25 & 0.62 \\
\hline
\end{tabular}

\subsection{Sequence Comparison of the Mutant K5 and Wild-type (WT) BnAHAS Genes}

Three functional BnAHAS genes (BnAHAS1, BnAHAS2 and BnAHAS3) were amplified in K5 and ZS9 by using previously reported primers to determine the critical mutation(s) responsible for the herbicide resistance of the mutant line K5 [29] (Table S3). In addition, BnAHAS1 was also amplified from five other susceptible lines, namely, Zhong 7, Zhong 2, QSC, Q7C and S11R. Results indicated that the BnAHAS2 and the BnAHAS3 sequences were identical between the lines ZS9 and K5. Notably, a novel single nucleotide polymorphism (SNP) was detected at position 544 in the BnAHAS1 coding region of $K 5$ with the alternation from $C$ to $T$ (Figure 3). The sequencing of BnAHAS1 in five other lines (Zhong 7, Zhong 2, QSC, Q7C and S11R) did not detect this SNP. These lines showed C as the ZS9 at position 544 in BnAHAS1. This mutant allele in the $K 5$ was designed as BnAHAS1 ${ }^{544 T}$, and its sequence was deposited in the GenBank (accession number: KP985786). The SNP at position 544 (C554T) led to a substitution of $\mathrm{P}$ with $\mathrm{S}$ at position 182 of BnAHAS1 (Figure 3), which corresponded to Pro-197 in AtAHAS. This finding suggested that this SNP was probably responsible for the herbicide-resistance of $K 5$.

\subsection{Development of Allele-Specific (AS) Markers and Co-Segregation Analysis}

Screening homozygous herbicide-resistant individuals with the mutant allele BnAHAS1 ${ }^{544 T}$ by spraying herbicides takes time, and using polymerase chain reaction (PCR)-based AS markers was expected to be a quick way to do such work. Therefore, several sets of AS-PCR primers were designed. One pair of AS-PCR markers (BnA1-F1 and BnA1-R4), which can distinguish homozygous-resistant individuals from heterozygous ones, was selected (Table S3). Given that the BnAHAS1 and BnAHAS3 were highly homologous to each other in their coding regions, the forward primer BnA1-F1 was designed in the $5^{\prime}$ UTR region of BnAHAS1 to avoid the amplification of BnAHAS3. The amplified products of the lines $K 5$ and ZS9 were approximately $805 \mathrm{bp}$ in length by the pair of primers BnA1-F1 and BnA1-R4. The lines ZS9 and $K 5$ shared an AvaII restriction site in the amplified products of $B n A H A S 1$ at position 465 . However, in the BnAHAS1 sequence of ZS9, another restriction site of $A v a I I$ was identified at position 544 , where the SNP was located. This restriction site can be used to distinguish the WT allele of BnAHAS1 from the mutant allele $B n A H A S 1^{544 T}$ in $K 5$. As a result, the amplified product of BnAHAS1 from ZS9 can be digested into three fragments with the lengths of 644, 81 and $80 \mathrm{bp}$, respectively. However, the agarose gel electrophoresis can only detect two bands: $644 \mathrm{bp}$ and about $80 \mathrm{bp}$ in length. Two fragments with the lengths of 644 and $161 \mathrm{bp}$ can be detected from the homozygous-resistant mutant (with allele $B n A H A S 1^{544 T}$ ). The heterozygous-resistant individuals showed three bands with lengths of 644,161 and $80 \mathrm{bp}$ on the agarose gel. The individual plants of 
ZS9 and $K 5$ with their corresponding $\mathrm{F}_{1}$ were detected with the AS-PCR marker, and results were perfectly obtained, as expected (Figure 4a). Moreover, the PCR amplification result of 30 susceptive B. napus accessions (Table S4) with this pair of AS-PCR primers displayed the same band pattern as the susceptible parent ZS9, which validated the specificity of this marker (Figure $4 b$ ).

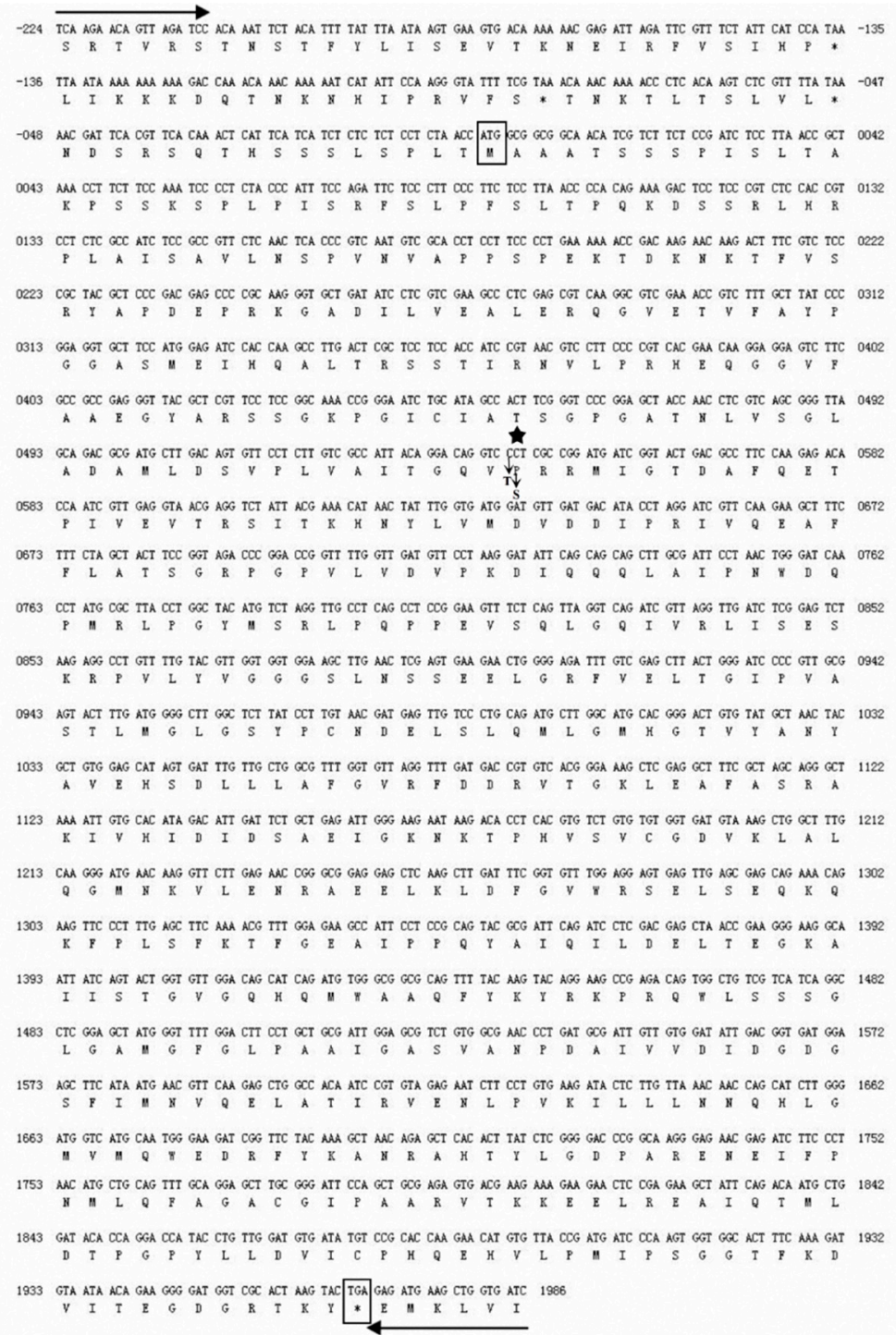

Figure 3. Mutant position of BnAHAS1 $1^{544 T}$ in the mutant K5. Primer nucleotide sequences for amplifying $B n A H A S 1$ are indicated by the forward and reverse arrows. The boxes represent the initiation or the stop codons of the BnAHAS1 ${ }^{544 T}$ gene. The star indicates the position $\left(544^{\text {th }}\right.$ of the $B n A H A S 1^{544 T}$ coding sequence in $\left.K 5\right)$ of the single base substitution from C-T. The amino acid is substituted from proline $(\mathrm{P})$ to serine $(\mathrm{S})$. 
(a)

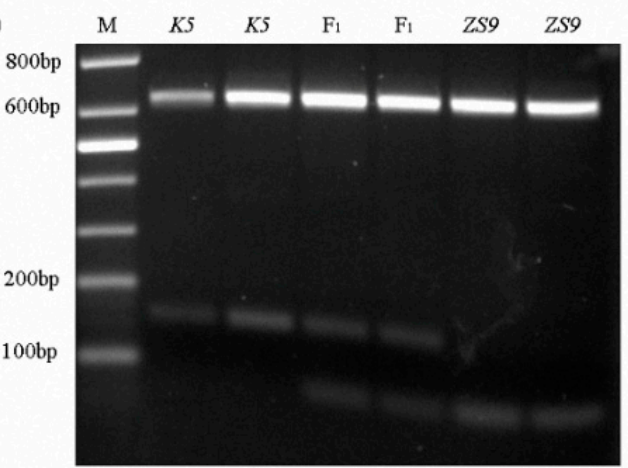

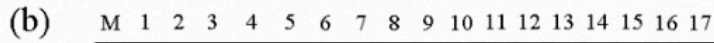

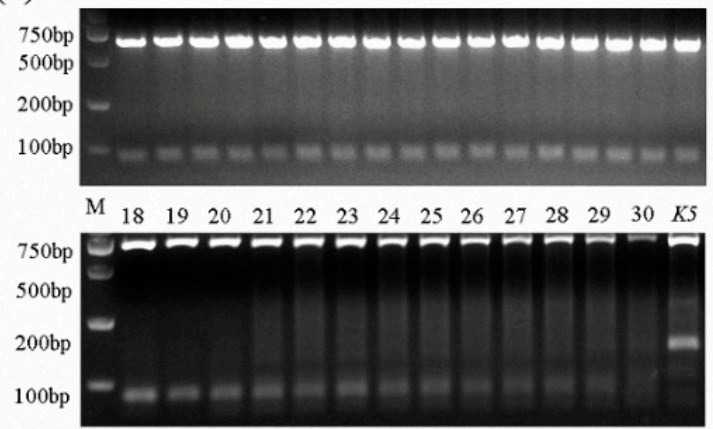

Figure 4. Development and verification of co-dominant AS-PCR markers. (a) Distinguishing susceptive and resistant parents and their $\mathrm{F}_{1 \mathrm{~s}}$. M, marker; ZS9, Zhongshuang No.9, the susceptive line and K5, the mutant resistant line. (b) Verification of AS-PCR markers in 30 susceptive accessions. M, marker; K5, the mutant resistant line and lanes 1-30, 30 rapeseed susceptive accessions (Table S4).

Co-segregation analysis was conducted using the AS-PCR marker in the $\mathrm{BC}_{1}$ population, which was derived from the cross between $K 5$ and ZS9, to figure out the relationship between herbicide resistance and the mutation $\left(B n A H A S 1^{544 T}\right)$ in $K 5$. The $\mathrm{BC}_{1}$ population was separated into half-resistant and susceptive plants after spraying $4.5 \mathrm{~g}$ a.i. $\mathrm{ha}^{-1} \mathrm{TBM}$. The $\mathrm{BC}_{1}$ population was detected in the $B n A H A S 1^{544} \mathrm{SNP}_{\mathrm{S}}$ by using the AS-PCR marker. The $\mathrm{BC}_{1}$ population of 273 individuals was evaluated, and results indicated that the AS-PCR markers co-segregated with the phenotyping results (Figure S3).

\subsection{Expression of BnAHAS1 ${ }^{544 T}$ Confers Herbicide Resistance in A. Thaliana Plants}

A binary expression vector containing BnAHAS1 $1^{544 T}$ was transformed into WT Arabidopsis to determine whether the mutant allele BnAHAS1 ${ }^{544 T}$ conferred TBM resistance. Five transgenic lines (TA1-1-TA1-5) were obtained. After being selfed for two generations, two homozygous lines (TA1-1 and TA1-4) were selected from the offspring and used for the following assays. First, these two homozygous lines were foliar sprayed with $0.3 \mathrm{~g}$ a.i. $\mathrm{ha}^{-1} \mathrm{TBM}$, and results indicated that these homozygous lines can tolerate this rate of TBM and did not show any symptoms, whereas WT plants died (Figure 5a). Second, the expression of BnAHAS1 in WT and TA1 was detected by semiquantitative PCR (SQ-PCR), and results revealed that the specific fragments of $B n A H A S 1^{544 T}$ can be amplified in the two transgenic lines. However, the fragment cannot be amplified in $W T$, which further verified that the mutated allele $B n A H A S 1^{544 T}$ contributed to the TBM resistance of $A$. thaliana (Figure $5 b$ ). Third, after spraying with different rates of TBM, the fresh weight of the transgenic line TA1-1 decreased gradually, although the rates used were higher than those for WT (Figure 5c), which showed a similar trend as rapeseed lines K5 and ZS9 after treated with TBM (Table S2). Collectively, BnAHAS1 ${ }^{544 T}$ was concluded to endure the K5 TBM resistance. 
(a)

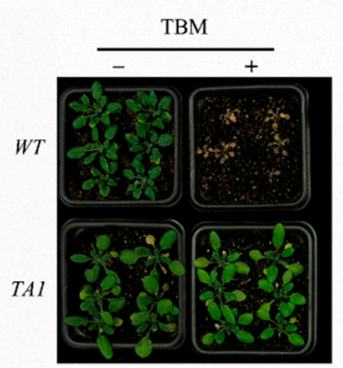

(b)

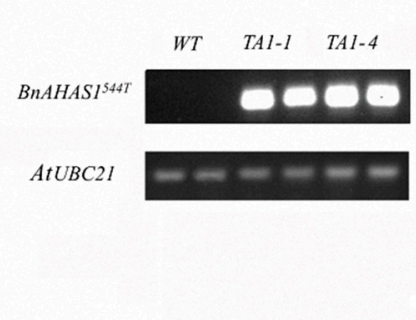

(c)

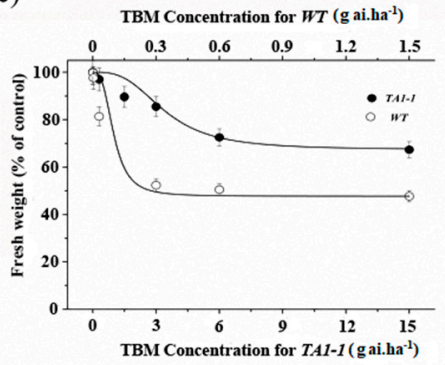

Figure 5. Tribenuron-methyl (TBM) resistance in transgenic Arabidopsis plants expressing the mutant allele BnAHAS1 $1^{544 T}$. (a) Phenotype of wild-type (WT) and transgenic Arabidopsis line (TA1) after spraying with $0.3 \mathrm{~g}$ a.i. $\mathrm{ha}^{-1}$ of TBM at the 4-6 leaf stage. (b) Expression analysis of the BnAHAS1 ${ }^{544 T}$ gene in WT and TA1 by semiquantitative PCR. AtUBC21, ubiquitin-conjugating enzyme 21. (c) Fresh weight inhibition of WT and TA1-1 two weeks after spraying with different rates of TBM.

\subsection{Development of a Method for Fast-screening TBM-Resistant Mutants in Greenhouse}

Developing a fast way for screening TBM-resistant mutants in a greenhouse is important, because finding natural or mutated herbicide-resistant individuals in field is a time- and labor-consuming work. The seeds of K5 and ZS9 were sown in pots and immediately irrigated with five and seven different rates of TBM, respectively, to investigate the suitable TBM rate for distinguishing resistant individuals from sensitive ones (see the Section 4.9). After 5-7 days, all treated seeds started to emerge, with no apparent difference between $K 5$ and ZS9. After two weeks, TBM rates at 0.0003 and $0.003 \mathrm{~g}$ a.i. ha ${ }^{-1}$ did not inhibit the seedling growth of ZS9. However, TBM rates $\geq 0.03 \mathrm{~g}$ a.i. ha ${ }^{-1}$ inhibited seedling growth before the first leaf appeared (Figure 6). For K5, all the TBM rates $\leq 0.15 \mathrm{~g}$ a.i. ha ${ }^{-1}$ did not inhibit seedlings growth. Some seedlings were slightly inhibited at a $0.75 \mathrm{~g}$ a.i. ha ${ }^{-1} \mathrm{TBM}$ rate, and seedling growth was inhibited at a $3.75 \mathrm{~g}$ a.i. $\mathrm{ha}^{-1} \mathrm{TBM}$ rate (Figure 6). In general, TBM rates of 0.03-0.75 $\mathrm{g}$ a.i. ha ${ }^{-1}$ could distinguish a TBM-resistant line (K5) from a TBM-susceptible line (ZS9). In view of the relative safety and effectiveness, $0.15 \mathrm{~g}$ a.i. $\mathrm{ha}^{-1} \mathrm{TBM}$ was utilized in further assays.
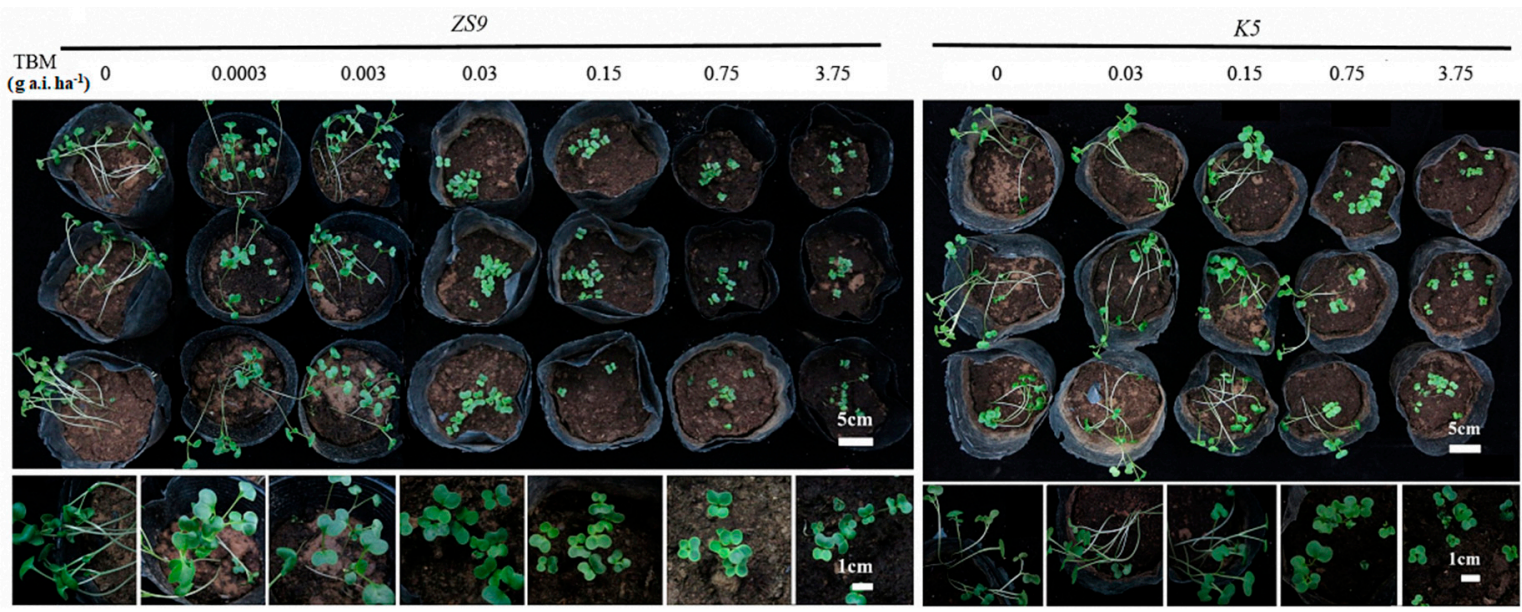

Figure 6. Phenotype of ZS9 and $K 5$ at the cotyledon stage after irrigating with tribenuron-methyl (TBM) solution. Seeds were sown in the pots, and each pot was immediately irrigated with $300 \mathrm{~mL}$ TBM solution at different rates. Photographs were taken two weeks after seed sowing. ZS9, Zhongshuang No.9 and K5, the mutant line.

Two parents, $K 5$ and $Z S 9$, and their derived $\mathrm{F}_{1}, \mathrm{BC}_{1}$ and $\mathrm{F}_{2}$ populations, were treated with $0.15 \mathrm{~g}$ a.i. ha ${ }^{-1} \mathrm{TBM}$ to verify the feasibility of this fast-screening method on the basis of the described procedure above. Two weeks later, the seedlings of the $\mathrm{F}_{1}$ population grew normally. However, a phenotypic separation was observed in $\mathrm{BC}_{1}$ and $\mathrm{F}_{2}$ populations. Part of the seedlings grew normally, 
and the other part grew abnormally, as the herbicide-susceptible parent ZS9 (Figure S4). The separation ratio of $\mathrm{BC}_{1}$ and $\mathrm{F}_{2}$ was analyzed (Table $\mathrm{S} 5$ ), and the result was consistent with the genetic investigation of TBM-resistance based on field data (Table 2). In addition, 50 resistant and 50 susceptible individuals were collected from the $\mathrm{BC}_{1}$ population, and these individuals were genotyped using the AS-PCR marker developed previously. Phenotyping and genotyping perfectly matched each other.

As a result, a fast way to screen TBM-resistant individuals in a greenhouse was developed. The seeds of a candidate rapeseed population were sown in pots and immediately irrigated with $0.15 \mathrm{~g}$ a.i. ha ${ }^{-1}$ TBM. Two weeks later, TBM-resistant and TBM-susceptible individuals can be distinguished on the basis of phenotyping.

\section{Discussion}

The use of herbicides is an effective and economic way to control weeds in rapeseed fields, and the successful control of weeds can avoid yield loss [27]. In China, the effective control of weeds has become an urgent challenge due to the rapid development of mechanization in rapeseed production. However, the availability of selective herbicides for rapeseed is quite limited due to a shortage of herbicide-resistant cultivars in China $[5,6]$. Finding new nontransgenic herbicide-resistant rapeseed materials is necessary due to the limitation of herbicide-resistant cultivars with independent intellectual property rights and the prohibition of commercial production of transgenic rapeseed in China. At present, many other crops are found harboring the AHAS-inhibiting herbicide resistance by nontransgenic ways due to the single-point mutation in $A H A S$ genes [25,30,31]. In addition, several rapeseed mutants conferring the AHAS-inhibiting herbicide resistance have been reported and proven due to mutations in BnAHASs, such as BnAHAS1-S653A [6,24], BnAHAS3-S197L [21] and BnAHAS3-T574L [24,32]. In our laboratory, seeds of rapeseed ZS9 (B. napus) are mutated through treatment with $1.0 \%(\mathrm{v} / \mathrm{v})$ EMS solution, and three TBM-resistant individuals are selected by the foliar spraying of the TBM solution $[5,28]$. In the previous study, the mutant line $K 5$ is a novel valuable germplasm for hybrid breeding through chemical hybridization agents, and the hypothesis that AHAS should be the target of the AHAS-inhibiting herbicide TBM when used as a chemical hybridization agent in rapeseed is supported [26]. In the present study, the inheritance and molecular characterization of the mutant line $K 5$ was carried out. Genetic results indicated that the resistance in $K 5$ was controlled by a dominant allele at a single nuclear gene locus, without a cytoplasmic effect. Molecular analysis revealed that a novel substitution of cytosine with thymine at the position 544 in BnAHAS1 was identified in the $K 5$ (this mutant allele in the $K 5$ was designed as $B n A H A S 1^{544 T}$ ), leading to the alteration of Per with Ser at position 182 in BnAHAS1 (correspondence to A. thaliana AtAHAS-197). The safety rate of TBM for $K 5$ growth was approximately $15 \mathrm{~g}$ a.i. $\mathrm{ha}^{-1}$, whereas that of ZS9 was lower than $0.15 \mathrm{~g}$ a.i. $\mathrm{ha}^{-1}$, indicating that the TBM resistance of $K 5$ was approximately 100 times that of ZS9 (Table 1). This mutant allele BnAHAS1 ${ }^{544 T}$ also conferred resistance to two other herbicides, BSM and MES. Collectively, the mutant $B n A H A S 1^{544 T}$ provided a novel invaluable resource for hybrid breeding by chemical hybridization agents and herbicide-resistance breeding in rapeseed.

The amino acid residue 197 of the AHAS enzyme, which makes up the SU binding pocket, is located at the fifth-helix in the $\alpha$ domain of the AHAS catalytic subunit and involved in anchoring the aromatic ring through hydrophobic interactions $[9,10]$. In addition, the substitution of P197 in AHAS has been reported to result in herbicide resistance in A. thaliana [33], soybean [31] and many weeds $[34,35]$. In the present study, the transgenic BnAHAS1 ${ }^{544 T}$ Arabidopsis experiment revealed that the overexpression of the BnAHAS1 $1^{544 T}$ allele conferred TBM resistance (Figure 5a). Furthermore, the AS-PCR markers, which were developed on the basis of the BnAHAS1 ${ }^{544 T}$ allele, were also co-segregated with herbicide resistance. Collectively, our experiments confirmed that the newly found substitution at position 182 of BnAHAS1 (correspondence to A. thaliana AtAHAS-197) in K5 provided herbicide resistance.

Herbicide-resistance mechanisms can be generally classified into two categories: target-site resistance (TRS) and non-target-site resistance (NSTR) [36]. The TSR mechanism largely involves 
mutation(s) in the target site of the action of an herbicide, resulting in an insensitive or less sensitive target protein of the herbicide $[19,36]$. The NTSR is endowed by any mechanism not belonging to the TSR, which include reduced herbicide uptake/translocation, increased herbicide metabolism, decreased rate of herbicide activation and/or sequestration [37,38]. Our experimental results indicated the herbicide-resistance in rapeseed mutant line $K 5$ is caused by the alteration of Per with Ser at position 182 in BnAHAS1, resulting in the less sensitive target protein BnAHAS1 of the herbicides. Therefore, the herbicide-resistance of the mutant $K 5$ belongs to the TSR. Whether TSR and NTSR mechanisms coexist in the mutant $K 5$ is necessary to investigate in the future [37]. It is expected that the "omics" strategy (genomics, transcriptomics, proteomics or metabolomics) will play an important role to unravel the genetic base of NTSR in rapeseed [38].

The availability of suitable molecular markers facilitated the effective screening of herbicide-resistant accessions in the rapeseed breeding program. Hu et al. [6] developed the AS-PCR marker to distinguish IMI-resistant materials, which contained the BnAHAS1-S653A resistant allele. Li et al. [21] developed the derived cleaved amplified polymorphic sequences (CAPS) marker to differentiate TBM-resistant materials, which contained the BnAHAS3-S197L allele. In addition, $\mathrm{Hu}$ et al. [32] developed the CAPS markers to differentiate a TBM- and IMI-resistant line M342, which contained the BnAHAS3-T574L resistant allele. In the present study, one pair of AS-PCR primers was developed on the basis of the restriction sites of the endonuclease AvaII, which can effectively identify homozygous and heterozygous individuals with the resistant $B n A H A S 1^{544 T}$ allele (Figure 4a). The AS-PCR marker also co-segregated with the herbicide resistance in the $\mathrm{BC}_{1}$ population derived from the cross between K5 and ZS9 (Figure S3), which suggested that this marker can be used in future rapeseed breeding for herbicide resistance.

Combination of marker-aided selection and fast-screening of herbicide-resistant seedlings in greenhouses will speed up the herbicide-resistant breeding program. Therefore, a method for fast-screening TBM-resistant materials in greenhouses, which employed $0.15 \mathrm{~g}$ a.i. $\mathrm{ha}^{-1} \mathrm{TBM}$ to irrigate pots that sow the candidate seed population of herbicide-resistance, was developed. After two weeks, the herbicide-resistance of the candidate population was assessed on the basis of the inhibition of seedling growth at the cotyledon stage (Figure 6). This method was applied to $\mathrm{F}_{2}$ and $\mathrm{BC}_{1}$ populations derived from the cross between K5 and ZS9. The phenotyping results corresponded well with the genotyping results by using our AS-PCR marker (Table S5). In addition, Magha et al. [39] employed a seed-soaking treatment to bioassay the herbicide-resistance of a rapeseed mutant and suggested that the method can be used to screen tolerant plants in inbreeding progenies or backcross-derived populations, as well as screen rapeseed mutants tolerant to herbicide in populations derived from seed mutagenesis. The seed-soaking treatment is successfully used in selecting soybean mutants tolerant to sulfonylureas [40,41]. Our method was similar to the seed-soaking method reported by Magha et al. [39]. The difference is that our method directly sowed seeds in pots and irrigated the pots with herbicide solution, which was slightly simpler than that reported by Magha et al. Simultaneously, a fast-screening method in the greenhouse was developed to select the herbicide-resistant individuals in the seedling stage for the herbicide breeding program.

\section{Materials and Methods}

\subsection{Plant Materials and Herbicides}

A total of 33 rapeseed (B. napus) accessions, namely, ZS9, K5, SH11 and 30 other rapeseed lines, were used in this investigation (Table S4). ZS9 was developed by the Oil Crops Research Institute of the Chinese Academy of Agricultural Sciences (Wuhan, China) and selfed for more than eight generations before use in the present study. K5 is a TBM-resistant mutant line derived from ZS9 via the EMS mutagenesis and obtained by TBM foliar spraying screening $[5,28]$. SH11 is an elite restorer line. The 30 rapeseed lines (Table S4) were used for AHAS sequence conformation and AS marker verification. By the end of September, all rapeseed materials were sown in the experimental 
field of Northwest A\&F University (N 34.29 ${ }^{\circ}$, E 108.06 $)$, Yangling, Shaanxi, China, in 2014-2017. Rapeseed materials were grown in 2.0-m-long rows with 0.5 and $0.1-\mathrm{m}$-spacing between and within rows, respectively. Before sowing, $600 \mathrm{~kg} \mathrm{ha}^{-1}$ of N, P and K compound fertilizer (N:P:K = 15:15:15) and $75 \mathrm{~kg} \mathrm{ha}^{-1}$ urea with a nitrogen content of $46.7 \%$ were applied as a basal fertilizer. At the end of December, rapeseed seedlings were watered for their overwintering. Rapeseed seedlings were sprayed accordingly with different herbicides at the 4-6 leaf stage. The resistance was evaluated 21 DAT.

A. thaliana (Col-0 ecotype) plants and its transgenic variants were grown at $22{ }^{\circ} \mathrm{C}$ under a 16-h light/8-h dark cycle (light intensity $70-150^{-2} \mathrm{~s}^{-1}$ ) and approximately $60 \%$ relative humidity in a phytotron.

The 10 different herbicides and their rates used in the present study are shown in Table 3. TBM (MaiFa ${ }^{\circledR}, 10 \%$ active ingredients); BSM (DaoWucao ${ }^{\circledR}, 10 \%$ active ingredients) and FU (FuMeiShi ${ }^{\circledR}$, $50 \mathrm{~g} \mathrm{~L}^{-1}$ active ingredients) were produced by Hetian Chemical Co. Ltd. (Shanyang, China); Kuaida Agrochemical Co. Ltd. (Jiangsu, China) and Agricultural Hormone Engineering Hormone Co. Ltd. (Jiangsu, China), respectively. MES (97.5\% active ingredients) was kindly provided by Professor Zhengming Li of NanKai University, Tianjin, China. Imidazole nicotinic (BaiLongTong ${ }^{\circledR}, 240 \mathrm{~g} \mathrm{~L}^{-1}$ active ingredients); CFE (FuShiMei ${ }^{\circledR}, 240 \mathrm{~g} \mathrm{~L}^{-1}$ active ingredients); SME (LvZhong ${ }^{\circledR}, 75 \%$ active ingredients); NSF (WuJingXiang ${ }^{\circledR}, 40 \mathrm{~g} \mathrm{~L}^{-1}$ active ingredients); glyphosate (ChuXinjie ${ }^{\circledR}, 80 \%$ active ingredients) and glufosinate (NuoDun ${ }^{\circledR}, 200 \mathrm{~g} \mathrm{~L}^{-1}$ active ingredients) were produced by LongDeng Chemical Co. Ltd. (Jiangsu, China); Plant Protectant Co. Ltd. (Suzhou, China); HuiFeng Agrochemical Co. Ltd. (Jiangsu, China); Plant Protection Institute of Chinese Academy of Agricultural Sciences Pharmaceutical Factory (Langfang, China); YunFan Chemical Co. Ltd. (JiangSu, China) and GuiHe Biotechnology Co. Ltd. (ShanDong, China), respectively.

Table 3. Herbicides and their rates in a volume of $300 \mathrm{~L} \mathrm{ha}^{-1}$ used for a cross-resistance test for the lines K5 and ZS9.

\begin{tabular}{|c|c|c|c|c|c|}
\hline Herbicides & $\begin{array}{c}\text { Rates for ZS9 } \\
\left(\mathrm{g} \text { a.i. } \mathrm{ha}^{-1}\right)\end{array}$ & $\begin{array}{r}\text { Rates for } K 5 \\
\text { (g a.i. ha }{ }^{-1} \text { ) }\end{array}$ & Herbicides & $\begin{array}{c}\text { Rates for ZS9 } \\
\left(\mathrm{g} \text { a.i. } \mathrm{ha}^{-1}\right)\end{array}$ & $\begin{array}{r}\text { Rates for } K 5 \\
\left(\mathrm{~g} \text { a.i. } \mathrm{ha}^{-1} \text { ) }\right.\end{array}$ \\
\hline \multirow{7}{*}{ Tribenuron-methyl } & 0 & 0 & \multirow{5}{*}{ Florasulam } & 0 & 0 \\
\hline & 0.06 & 3 & & 0.6 & 6 \\
\hline & 0.15 & 6 & & 1.5 & 9 \\
\hline & 0.3 & 15 & & 3 & 15 \\
\hline & 0.6 & 30 & & 0 & 0 \\
\hline & 1.5 & 60 & \multirow{3}{*}{$\begin{array}{c}\text { Sulfometuron } \\
\text { methyl ester }\end{array}$} & 150 & 150 \\
\hline & 3 & 150 & & 300 & 300 \\
\hline \multirow{5}{*}{ Bensufuron-methyl } & 0 & 0 & & 600 & 600 \\
\hline & 0.15 & 4.5 & \multirow{4}{*}{ Nicosulfuron } & 0 & 0 \\
\hline & 0.3 & 13.5 & & 13.5 & 13.5 \\
\hline & 0.6 & 18 & & 27 & 27 \\
\hline & 1.5 & 27 & & 54 & 54 \\
\hline \multirow{6}{*}{ Carfentrazone-ethyl } & 3 & - & \multirow{8}{*}{$\begin{array}{l}\text { Monosulfuron-ester } \\
\text { sodium }\end{array}$} & - & - \\
\hline & 4.5 & - & & - & - \\
\hline & 0 & 0 & & 0 & 0 \\
\hline & 1.5 & 1.5 & & 0.1 & 5 \\
\hline & 3 & 3 & & 0.2 & 10 \\
\hline & 4.5 & 4.5 & & 0.5 & 20 \\
\hline \multirow{3}{*}{ Imidazole nicotinic } & 0 & 0 & & 1 & 30 \\
\hline & 49.5 & 49.5 & & 2 & 50 \\
\hline & - & - & \multirow{6}{*}{ Glufosinate } & 5 & - \\
\hline \multirow{5}{*}{ Glyphosate } & - & - & & 10 & - \\
\hline & 0 & 0 & & 0 & 0 \\
\hline & 15 & 15 & & 6 & 6 \\
\hline & 21 & 21 & & 9 & 9 \\
\hline & 27 & 27 & & 15 & 15 \\
\hline
\end{tabular}




\subsection{Cross-Resistance of the Mutant line K5 to Different Herbicides}

Ten different herbicides were used to treat the seedlings of rapeseed lines K5 and ZS9 at the 4-6 leaf stage at different rates (Table 3). 21 DAT, the symptoms were recorded in accordance with the method described by Gao et al. [42]_ENREF_32. The following indices were scored for each herbicide treatment. Phytotoxicity was scored at seven grading standards: 0 , all leaves are green; 1 , young leaves (the first and second ones) are light yellow-green; 2, part of young leaves are yellow; 3 , the second leaf is yellow and curly; 4 , the mature leaves are yellow-green or light purple; 5 , certain mature leaves are dead and 6, the plant is dead. The phytotoxicity index was calculated using the following formula:

$$
\text { Phytotoxicity index }=\sum \frac{\text { score of the standard } \times \text { No. of plants for correspongding standard }}{\text { total No. of plants } \times 7}
$$

The leaf angle, leaf numbers and fresh and dry weights were investigated in accordance with the method described by Xin et al. [43].

The experiments were conducted in 2017. The field trials were arranged in a completely random block design with three replications for each line. Each plot contained four 2.0-m-length rows, with 0.5 and 0.1-m-spacing between and within rows, respectively. All traits were recorded from 10 seedlings for each replication, and the trait value was represented by the average data of 10 seedlings.

\subsection{Enzyme Extraction and Assays of AHAS Activity}

In 2017, the rapeseed seedlings of the lines ZS9 and K5 at the 4-6 leaf stage were sprayed with three different herbicides (TBM, BSM and MES) at different rates (Table 3). The leaves from 10 seedlings of each herbicide rate treatment of both lines were collected 21 DAT, and the AHAS enzyme activity was assayed on the basis of the protocol of Lv et al. [26]. The specific activities of AHAS of both lines were estimated by using the zero-herbicide control. The AHAS enzyme extracted from the controls of both lines was also used for the in vitro assay of the AHAS enzyme in accordance with the protocol of $\mathrm{Li}$ et al. [21]. The concentrations of TBM used in the in vitro assay were $0,1,2,5,10$ and $20 \mathrm{mg} \mathrm{L}^{-1}$. Three biological replications were included for each assay. The data from each line were fitted to a nonlinear regression model by using the curve fit of the SigmaPlot 12.0 software (Systat Software, San Jose, CA, USA). The nonlinear regression was based on a logistic function that was previously described mathematically [44]:

$$
y=C-(D-C) /\left[1+x / I_{50}\right]^{b}
$$

where $y$ is the AHAS activity (\% of the mean of the zero herbicide control), $x$ is the concentration of TBM used in the enzyme assay, $C$ and $D$ are the lower and upper asymptotes, respectively, of the AHAS activity, $I_{50}$ is the herbicide dose required to reduce the AHAS activity by $50 \%$ and $b$ is the slope of the curve at approximately $I_{50}$. The means of each treatment were estimated using the PROC ANOVA of the IBM SPSS Statistics 20.0 [45] and plotted on the logistic dose-response curves.

\subsection{Genetic Analysis of TBM-Resistance in the Mutant K5}

The mutant line K5 was crossed with the lines ZS9 and SH11 to develop $\mathrm{F}_{1}$. $\mathrm{F}_{1}$ plants were self-pollinated and backcrossed to the susceptible parents to obtain the $\mathrm{F}_{2}$ and $\mathrm{BC}_{1}$ generations, respectively. By the end of September of the two crop seasons of 2016-2017, the seeds of all the materials, including parents, $\mathrm{F}_{1}, \mathrm{~F}_{2}$ and $\mathrm{BC}_{1}$ progenies, were sown in the experimental field of Northwest A\&F University. At the 4-6 leaf stage, the seedlings of the abovementioned rapeseed materials were sprayed with $4.5 \mathrm{~g}$ a.i. ha ${ }^{-1} \mathrm{TBM}$ in a volume of $300 \mathrm{~L} \mathrm{ha}^{-1}$. The resistance of the parents and their progenies was evaluated 21 DAT. Plants were scored as resistant when no herbicide damage or only slight injury was observed and sensitive when the plants died. The segregation of each population was assessed using the chi-square $\left(\chi^{2}\right)$ goodness-of-fit test. 


\subsection{Amplification and Sequence Analysis of BnAHASs}

The genomic DNA of seven rapeseed lines, namely, ZS9, K5, Zhong 7, Zhong 2, QSC, Q7C and S11R (Table S4), were extracted from $0.5 \mathrm{~g}$ young leaves by using the cetyltrimethyl ammonium bromide method [46] and used as a template for the PCR amplification of BnAHAS1, BnAHAS2 and BnAHAS3 by the three pairs of primers reported by Hu et al. [29] (Table S3). The PCR mixture (20 $\mu \mathrm{L})$ contained 50 ng template DNA, $150 \mu \mathrm{M}$ dNTPs, $1 \times$ PCR buffer, $0.15 \mu \mathrm{M}$ each primer and $0.25 \mathrm{U}$ EX Taq DNA polymerase (Takara, China). PCR amplification was carried out by predenaturation at $94{ }^{\circ} \mathrm{C}$ for $5 \mathrm{~min}$ followed by 35 cycles at $94{ }^{\circ} \mathrm{C}$ for $30 \mathrm{~s}, 54^{\circ} \mathrm{C}$ for $40 \mathrm{~s}, 72{ }^{\circ} \mathrm{C}$ for $140 \mathrm{~s}$ and a final extension at $72{ }^{\circ} \mathrm{C}$ for $10 \mathrm{~min}$. The PCR amplification experiment was conducted in triplicate for each of the three BnAHAS genes. The PCR products were purified from agarose gel using the Gel Extraction Kit (TianGen, China). Subsequently, PCR products were ligated to the PMD $^{\text {TM }}$ 19T Vector (Takara, China) and transformed into DH $5 \alpha$ competent cells. Five positive clones from each PCR product of each BnAHAS gene were selected for sequencing by the ShengGong Company (Shanghai, China).

The obtained sequences were analyzed using the DNAMAN 6.0. The AHAS sequence of $A$. thaliana (At3g48560) was downloaded from TAIR [47]. Multiple sequence alignments were performed using the BioEdit 7.0 [48].

\subsection{Development of CAPS Markers for BnAHAS1 $1^{544}$}

The sequence comparison of BnAHASs revealed that the nucleotide sequence 540-544 bps from the translation starting site in the WT allele of BnAHAS1 in the line ZS9 was GGTCC, which was mutated to GGTCT in the mutant line K5 (see Section 2.5). Therefore, the restriction endonuclease AvaII with the restriction sites GGWCC was employed to develop the CAPS marker for the detection of the causal point mutation in BnAHAS1. A pair of AS-PCR primers (BnA1F1 and BnA1R4, Table S3) was designed to amplify the target sequence containing the mutant locus. The PCR mixture $(40 \mu \mathrm{L})$ contained $100 \mathrm{ng}$ template DNA, $0.75 \mu \mathrm{M}$ for each primer and $20 \mu \mathrm{L}$ Primer Star Max (Takara, China). PCR amplification was carried out with 36 cycles at $98^{\circ} \mathrm{C}$ for $10 \mathrm{~s}, 56^{\circ} \mathrm{C}$ for $5 \mathrm{~s}$ and $72{ }^{\circ} \mathrm{C}$ for $10 \mathrm{~s}$. All PCR products were digested with $10 \mathrm{U}$ AvaII (New England Biolabs, Ipswich, MA, USA) for about $30 \mathrm{~min}$ at $37^{\circ} \mathrm{C}$ at a final volume $25 \mu \mathrm{L}$. Subsequently, the products were separated on $2.5 \%$ agarose gel, stained with ethidium bromide and visualized using a gel imaging system (Alpha Innotech, Shanghai, China).

\subsection{Arabidopsis Transformation and TBM Treatment}

The BnAHAS1 $1^{544 T}$ from the positive pMD19T-BnAHAS1 ${ }^{544 T}$ clone was first prepared by a fusion PCR with two pairs of primers (ahas1NcoI-F and ahas1NcoI-R and ahas1Blunt-F and ahas1Blunt-R) to avoid the restriction sites of NcoI in BnAHAS1 (Table S3), which was then introduced into the expression vector pCAMBIA3301 by using the NcoI and PmII double-digested method. The final overexpression vector was transformed into Agrobacterium tumefaciens GV3101. The obtained positive clones were used to introduce BnAHAS1 ${ }^{544 T}$ into A. thaliana (Col-0) by using the floral dip transformation method [49]. The herbicide Basta was employed for screening positive transgenic plants. The obtained positive lines were treated with $0.3 \mathrm{~g}$ a.i. $\mathrm{ha}^{-1} \mathrm{TBM}$ at the 4-6 leaf stage to determine whether $B n A H A S 1^{544 T}$ was the causal resistance allele to TBM. For the fresh weight assay, the obtained positive lines were treated with $0,1.5,3.0,6.0$ and $15.0 \mathrm{~g}$ a.i. $\mathrm{ha}^{-1} \mathrm{TBM}$, and WT A. thaliana (WT) plants were treated with 0.003 , $0.03,0.3,0.6$ and $1.5 \mathrm{~g}$ a.i. $\mathrm{ha}^{-1} \mathrm{TBM}$ with a volume of $0.5 \mathrm{~mL}$ for each plant.

\subsection{RNA Extraction and $S Q-P C R$}

The young leaves of the homozygous BnAHAS1 $1^{544 T}$ transgenic and WT A. thaliana plants were collected for RNA isolation by using the plant RNA extraction kit (E.Z.N.A. ${ }^{\circledR}$ Plant RNA Kit, R6827-01, Omega Bio-Tek, Norcross, GA, USA). The GoScript TM Reverse Transcription System (A5001, Promega, Madison, WI, USA) was utilized for the synthesis of the first-strand cDNA. The SQ-PCR primers TA1-F and TA1-R (Table S3) were used to amplify the BnAHAS1. The housekeeping gene ubiquitin-conjugating 
enzyme 21 (UBC21) was employed as the reference gene. The SQ-PCR primers, UBC_qPCR-F and UBC_qPCR-R (Table S3), were used to amplify UBC21.

\subsection{Fast-Screening Method for TBM-Resistant Rapeseed in Greenhouse}

The seeds of rapeseed lines $Z S 9$ and $K 5$ and their $\mathrm{F}_{1}, \mathrm{BC}_{1}$ and $\mathrm{F}_{2}$ were prepared. Field soil and commercial-scale substrate soil (Pindstru, Ryomgaard, Denmark) were mixed at a ratio of 1:1 and subsequently filled into pots $\left(18 \times 16 \mathrm{~cm}^{2}\right)$. Each pot was sown with $10-15$ seeds and irrigated with a $300 \mathrm{~mL}$ TBM solution at different dosages. The mutant line $K 5$ was treated with $0,0.03,0.15,0.75$ and $3.75 \mathrm{~g}$ a.i. $\mathrm{ha}^{-1} \mathrm{TBM}$ solution, whereas the line ZS9 was treated with $0,0.0003,0.003,0.03,0.15,0.75$ and $3.75 \mathrm{~g}$ a.i. $\mathrm{ha}^{-1} \mathrm{TBM}$ solution. Finally, the $0.15 \mathrm{~g}$ a.i. $\mathrm{ha}^{-1} \mathrm{TBM}$ was used to test the herbicide resistance of the $\mathrm{F}_{1}, \mathrm{BC}_{1}$ and $\mathrm{F}_{2}$ derived from the parent lines $Z S 9$ and $K 5$ on the basis of the abovementioned results. All plants were cultivated in a $25^{\circ} \mathrm{C} / 10^{\circ} \mathrm{C}$ (day/night) phytotron with a 16 -h light/8-h dark cycle (light intensity of 4000-6000 lx).

\subsection{Data analysis}

The independent-sample $t$-test was employed to compare the $I_{50}$ values of fresh and dry weights between the two lines by using the SPSS 20.0 [45]. A completely randomized design and one-way ANOVA were performed using the SPSS 20.0 software to analyze the tested traits (phytotoxicity index, the leaf angle, leaf number, fresh and dry weights) and AHAS relative activity [45], with herbicide treatment as the fixed factor and biological replication as the random factor. The means of the treatments were compared using the Tukey method.

\section{Conclusions}

The rapeseed mutant line K5 acquired its herbicide resistance from the mutation of BnAHAS1 ${ }^{544 T}$, leading to the Pro-182-Ser alteration in BnAHAS1. In addition, the AS-CAPS marker was developed on the basis of the mutant allele BnAHAS1 $1^{544 T}$ and the method for fast-screening TBM-resistant plants in the candidate population at the cotyledon stage, which may promote the future development of herbicide-resistant rapeseed cultivars.

Supplementary Materials: Supplementary materials can be found at http:/www.mdpi.com/1422-0067/21/4/1345/ s1. Figure S1. Phenotype of K5 and ZS9 plants 21 days after being sprayed with different rates of three different herbicides. ZS9, Zhongshuang No.9 and K5, the mutant line. Figure S2. In vitro relative AHAS activity of rapeseed ZS9 and mutant K5 treated with different concentrations of tribenuron-methyl (TBM). ZS9, Zhongshuang No.9 and $K 5$, the mutant line. Figure S3. Segregation of the AS-PCR markers in homozygous and heterozygous plants in the $\mathrm{BC}_{1}$ population derived from $K 5$. M, marker; RS, resistant heterozygote individuals and S, susceptible homozygous individuals. Figure S4. Genetic investigation of herbicide resistance in $K 5$ by the quick screening method in the greenhouse. Seeds were sown in the pots, and each pot was immediately irrigated with a $300 \mathrm{~mL}$ $0.15 \mathrm{~g}$ a.i. ha ${ }^{-1}$ tribenuron-methyl (TBM) solution. Photographs were taken two weeks after spraying TBM. Table S1. Analysis of variance of five indexes of lines K5 and ZS9. Table S2. Effects of foliar spraying of three different herbicides on the morphological traits of the lines ZS9 and K5. Table S3. Primers used in the present study. Table S4. Rapeseed (Brassica napus L.) accessions used for AHAS sequence conformation and verification. Table S5. Inheritance of the tribenuron-methyl resistance in the mutant line $K 5$ by the fast-screening method.

Author Contributions: Q.H. performed the experiments, analyzed the data and drafted the manuscript. J.L., Y.S. and H.W. helped in performing the experiments. S.H. and G.Q. provided the plant materials. Y.G. helped in analyzing the data. S.H. conceived the study and wrote the manuscript. All authors read and approved the final manuscript.

Funding: This research was supported by the earmarked fund for the China Agriculture Research System (CARS-13), the Key R\&D project of Shaanxi Province (2018ZDXM-NY-008), the Modern Crop Seed Industry project of Shaanxi Province (20171010000004) and the open project of the State Key Laboratory of Crop Stress Biology for Arid Areas (CSBAA2017002).

Acknowledgments: We express deep gratitude to Zhengming Li of NanKai University, Tianjin, China for providing the monosulfuron-ester sodium, an AHAS-inhibiting herbicide.

Conflicts of Interest: The authors declare no competing interests. 


\section{Abbreviations}

$\begin{array}{ll}\text { AHAS } & \text { Acetohydroxyacid synthase } \\ \text { AS } & \text { Allele-specific } \\ \text { A. thaliana } & \text { Arabidopsis thaliana } \\ \text { B. napus } & \text { Brassica napus L. } \\ \text { BSM } & \text { Bensufuron-methyl } \\ \text { CFE } & \text { Carfentrazone-ethyl } \\ \text { CAPS } & \text { Cleaved amplified polymorphic sequences } \\ \text { DAT } & \text { Days after treatments } \\ \text { EMS } & \text { Ethyl methyl sulfonate } \\ \text { FU } & \text { Florasulam } \\ \text { NSF } & \text { Nicosulfuron } \\ \text { IMI } & \text { Imidazolinones } \\ \text { MES } & \text { Monosulfuron-ester sodium } \\ \text { NSTR } & \text { Non-target-site resistance } \\ \text { PCR } & \text { Polymerase chain reaction } \\ \text { SU } & \text { Sulfonylureas } \\ \text { SME } & \text { Sulfometuron methyl ester } \\ \text { SNP } & \text { Single nucleotide polymorphisms } \\ \text { TRS } & \text { Target-site resistance } \\ \text { TBM } & \text { Tribenuron-methyl } \\ \text { UBC21 } & \text { Ubiquitin-conjugating enzyme 21 } \\ \text { ZS9 } & \text { Zhongshuang No.9 }\end{array}$

\section{References}

1. Agriculture Usdo. Available online: https://www.usda.gov/ (accessed on 20 October 2018).

2. Peschken, D.P.; Thomas, A.G.; Wise, R.F. Loss in yield of rapeseed (Brassica napus, B. campestris) caused by perennial Sowthistle (Sonchus arvensis) in Saskatchewan and Manitoba. Weed Sci. 1983, 31, 740-744. [CrossRef]

3. Boström, U. Response of weeds and crop yield to herbicide dose decision-support guidelines. Weed Sci. 2009, 50, 186-195. [CrossRef]

4. Freeman, S.E.; Lutman, P.J.W. The effects of timing of control of weeds on the yield of winter oilseed rape (Brassica napus), in the context of the potential commercialization of herbicide-tolerant winter rape. J. Agric. Sci. 2004, 142, 263-272. [CrossRef]

5. Sun, Y.Y.; Qu, G.P.; Huang, Q.X.; Lv, J.Y.; Guo, Y.; Wu, H.S. SNP markers for acetolactate synthase genes from tribenuron-methyl resistant mutants in Brassica napus L. Chin. J. Oil Crop Sci. 2015, 37, 589-595.

6. Hu, M.; Pu, H.; Kong, L.; Gao, J.; Long, W.; Chen, S.; Zhang, J.; Qi, C. Molecular characterization and detection of a spontaneous mutation conferring imidazolinone resistance in rapeseed and its application in hybrid rapeseed production. Mol. Breed. 2015, 35, 46-50. [CrossRef]

7. Zhang, H.J.; Liu, X.; Zhang, J.; Cui, H.L.; Zhang, C.X.; Zhu, W.D. Registration and use of herbicides in rapeseed fields in China. Sci. Technol. Innov. Her. 2008, 15, 252-253.

8. Heap, I. Global perspective of herbicide-resistant weeds. Pest Manag. Sci. 2014, 70, 1306-1310. [CrossRef]

9. Duggleby, R.G.; Mccourt, J.A.; Guddat, L.W. Structure and mechanism of inhibition of plant acetohydroxyacid synthase. Plant Physiol. Biochem. 2008, 46, 309-324. [CrossRef]

10. Mccourt, J.A.; Duggleby, R.G. Acetohydroxyacid synthase and its role in the biosynthetic pathway for branched-chain amino acids. Amino Acids 2006, 31, 173-210. [CrossRef]

11. Duggleby, R.G.; Pang, S.S. Acetohydroxyacid Synthase. BMM Rep. 2000, 33, 1-36.

12. Kleschick, W.A.; Costales, M.J.; Dunbar, J.E.; Meikle, R.W.; Monte, W.T.; Pearson, N.R.; Snider, S.W.; Vinogradoff, A.P. New herbicidal derivatives of 1,2,4-triazolo[1,5-a]pyrimidine. Pest Manag. Sci. 2010, 29, 341-355. [CrossRef]

13. Santel, H.J.; Bowden, B.A.; Sorensen, V.M.; Mueller, K.H. Flucarbazone-Sodium-A New Herbicide for the Selective Control of Wild Oat and Green Foxtail in Wheat; British Crop Protection Council: Farnham, UK, 1999. 
14. Shaner, D.L.; Anderson, P.C.; Stidham, M.A. Imidazolinones: Potent inhibitors of acetohydroxyacid synthase. Plant. Physiol 1984, 76, 545-546. [CrossRef]

15. Ray, T. Site of action of chlorsulfuron: inhibition of valine and isoleucine biosynthesis in plants. Plant Physiol. 1984, 75, 827. [CrossRef] [PubMed]

16. Xu, X.; Wang, G.Q.; Chen, S.L.; Fan, C.Q.; Li, B.H. Confirmation of flixweed (Descurainia sophia) resistance to tribenuron-methyl using three different assay methods. Weed Sci. 2010, 58, 56-60. [CrossRef]

17. Xu, X.; Liu, G.; Chen, S.; Li, B.; Liu, X.; Wang, X.; Fan, C.; Wang, G.; Ni, H. Mutation at residue 376 of ALS confers tribenuron-methyl resistance in flixweed (Descurainia sophia) populations from Hebei Province, China. Pestic. Biochem. Physiol. 2015, 125, 62-68. [CrossRef] [PubMed]

18. International Survey of Herbicide Resistant Weeds. Available online: http://www.weedscience.org/Mutations/ MutationDisplayAll.aspx (accessed on 1 May 2018).

19. Murphy, B.; Tranel, P. Target-site mutations conferring herbicide resistance. Plants 2019, 8, 382. [CrossRef]

20. Rutledge, R.G.; Quellet, T.; Hattori, J.; Miki, B.L. Molecular characterization and genetic origin of the Brassica napus acetohydroxyacid synthase multigene family. Mol. Gen. Genet. 1991, 229, 31-40. [CrossRef] [PubMed]

21. Li, H.; Li, J.; Zhao, B.; Wang, J.; Yi, L.; Liu, C.; Wu, J.; King, G.J.; Liu, K. Generation and characterization of tribenuron-methyl herbicide-resistant rapeseed (Brasscia napus) for hybrid seed production using chemically induced male sterility. Theor. Appl. Genet. 2015, 128, 107-118. [CrossRef]

22. Hattori, J.; Brown, D.; Mourad, G.; Labbé, H.; Ouellet, T.; Sunohara, G.; Rutledge, R.; King, J.; Miki, B. An acetohydroxy acid synthase mutant reveals a single site involved in multiple herbicide resistance. Mol. Gen. Genet. 1995, 246, 419-425. [CrossRef]

23. Tonnemaker, K.A.; Auld, D.L.; Thill, D.C.; Mallorysmith, C.A.; Erickson, D.A. Development of sulfonylurea-resistant rapeseed using chemical mutagenesis. Crop. Sci. 1992, 32, 1387-1391. [CrossRef]

24. Swanson, E.B.; Herrgesell, M.J.; Arnoldo, M.; Sippell, D.W.; Wong, R.S.C. Microspore mutagenesis and selection: Canola plants with field tolerance to the imidazolinones. Theor. Appl. Genet. 1989, 78, 525-530. [CrossRef] [PubMed]

25. Tan, S.; Evans, R.R.; Dahmer, M.L.; Singh, B.K.; Shaner, D.L. Imidazolinone-tolerant crops: history, current status and future. Pest Manag. Sci. 2005, 61, 246. [CrossRef] [PubMed]

26. Lv, J.; Huang, Q.; Sun, Y.; Qu, G.; Guo, Y.; Zhang, X.; Zhao, H.; Hu, S. Male sterility of an AHAS-mutant induced by tribenuron-methyl solution correlated with the decrease of AHAS activity in Brassica napus L. Front. Plant Sci. 2018, 9, 1014. [CrossRef] [PubMed]

27. Harker, K.N.; Clayton, G.W.; O’Donovan, J.T.; Blackshaw, R.E.; Stevenson, F.C. Herbicide timing and rate effects on weed management in three herbicide-resistant Canola systems. Weed Technol. 2009, 18, 1006-1012. [CrossRef]

28. Qu, G.P.; Sun, Y.Y.; Pang, H.X.; Qiang, W.U.; Wang, F.L.; Hu, S.W. EMS mutagenesis and ALS-inhibitor herbicide-resistant mutants of Brassica napus L. Chin. J. Oil Crop Sci. 2014, 36, 25-31.

29. Hu, M.L.; Pu, H.M.; Gao, J.Q.; Long, W.H.; Qi, C.K.; Zhang, J.F.; Chen, S. Inheritance and gene cloning of an ALS Inhabiting herbicide-resistant mutant line M9 in Brassica napus. Sci. Agric. Sin. 2012, 35, 4326-4334.

30. Shoba, D.; Raveendran, M.; Manonmani, S.; Utharasu, S.; Dhivyapriya, D.; Subhasini, G.; Ramchandar, S.; Valarmathi, R.; Grover, N.; Krishnan, S.G. Development and genetic characterization of a novel herbicide (imazethapyr) tolerant mutant in Rice (Oryza sativa L.). Rice 2017, 10, 10-17. [CrossRef]

31. Ghio, C.; Ramos, M.L.; Altieri, E.; Bulos, M.; Sala, C.A. Molecular characterization of Als1, an acetohydroxyacid synthase mutation conferring resistance to sulfonylurea herbicides in soybean. Theor. Appl. Genet. 2013, 126, 2957-2968. [CrossRef]

32. Hu, M.L.; Pu, H.M.; Gao, J.Q.; Long, W.H.; Chen, F.; Zhou, X.Y.; Zhang, W.; Peng, Q.; Chen, S.; Zhang, J.F. Inheritance and molecular characterization of resistance to AHAS-inhibiting herbicides in rapeseed. J. Integr. Agric. 2017, 16, 2421-2433. [CrossRef]

33. Haughn, G.W.; Smith, J.; Mazur, B.; Somerville, C. Transformation with a mutant Arabidopsis acetolactate synthase gene renders tobacco resistant to sulfonylurea herbicides. Mol. Gen. Genet. 1988, 211, $266-271$. [CrossRef]

34. Nakka, S.; Thompson, C.R.; Peterson, D.E.; Jugulam, M. Target site-based and non-target site based resistance to ALS inhibitors in Palmer Amaranth (Amaranthus palmeri). Weed Sci. 2018, 65, 1-9. [CrossRef] 
35. Ntoanidou, S.; Kaloumenos, N.; Diamantidis, G.; Madesis, P.; Eleftherohorinos, I. Molecular basis of Cyperus difformis cross-resistance to ALS-inhibiting herbicides. Pestic. Biochem. Physiol. 2016, 127, 38-45. [CrossRef] [PubMed]

36. Délye, C.; Jasieniuk, M.; Corre, V. Deciphering the evolution of herbicide resistance in weeds. Trends Genet. 2013, 29, 649-658. [CrossRef] [PubMed]

37. Jugulam, M.; Shyam, C. Non-target-site resistance to herbicides: recent developments. Plants 2019, 8, 417. [CrossRef]

38. Délye, C. Unravelling the genetic bases of non-target-site-based resistance (NTSR) to herbicides: A major challenge for weed science in the forthcoming decade. Pest Manag. Sci. 2013, 69, 176-187. [CrossRef]

39. Magha, M.I.; Guerche, P.; Bregeon, M.; Renard, M. Characterization of a spontaneous rapeseed mutant tolerant to sulfonylurea and imidazolinone herbicides. Plant Breed. 1993, 111, 132-141. [CrossRef]

40. Sebastian, S.A.; Fader, G.M.; Ulrich, J.F.; Forney, D.R.; Chaleff, R.S. Semidominant soybean mutation for resistance to sulfonylurea herbicides. Crop Sci. 1989, 29, 1403-1408. [CrossRef]

41. Sebastian, S.A.; Chaleff, R.S. Soybean mutants with increased tolerance for sulfonylurea herbicides. Crop Sci. 1987, 27, 948-952. [CrossRef]

42. Gao, J.Q.; Pu, H.M.; Long, W.H.; Hu, M.L.; Qi, C.K.; Zhang, J.F. Resistance of imidzolidone-resistant oilseed rape to nonselective herbicide imazethapyr. Jiangsu J. Agric. Sci. 2010, 26, 1186-1191.

43. Xin, X.; Qu, G.; Zhang, R.; Pang, H.; Wu, Q.; Wang, F.; Hu, S. Identification of the tribenuron-methyl tolerance in different rapeseed genotypes. Acta Agric. Boreali-Occident. Sin. 2014, 23, 68-74.

44. Seefeldt, S.S.; Fuerst, E.P. Log-logistic analysis of herbicide dose-response relationships. Weed Technol. 1995, 9, 218-227. [CrossRef]

45. IBM Corp. IBM SPSS Statistics for Windows, Version 20.0; IBM Corp: New York, NY, USA, 2013.

46. Doyle, J.; Doyle, J. A rapid total DNA preparation procedure for fresh plant tissue. Focus 1990, 12, 13-15.

47. The Arabidopsis Information Resource. Available online: https://www.arabidopsis.org/ (accessed on 1 May 2018).

48. Hall, T.A. BioEdit: a user-friendly biological sequence alignment editor and analysis program for Windows 95/98/NT. Nucleic Acids Symp. Ser. 1999, 41, 95-98.

49. Zhang, X.; Henriques, R.; Lin, S.S.; Niu, Q.W.; Chua, N.H. Agrobacterium-mediated transformation of Arabidopsis thaliana using the floral dip method. Nat. Protoc. 2006, 1, 641-646. [CrossRef] [PubMed] 